Hermus, M., Boesveld, I., Pal-de Bruin, K.M. van der, Wiegers, T. Development of the optimality index-NL2015, an instrument to measure outcomes of maternity care. Journal of Midwifery \& Women's Health: 2017, 62(5), 580-588

\begin{tabular}{|l|l|}
$\begin{array}{l}\text { Postprint } \\
\text { Version }\end{array}$ & 1.0 \\
\hline Journal website & $\underline{\text { http://dx.doi.org/10.1111/imwh.12650 }}$ \\
\hline Pubmed link & $\underline{\text { https://www.ncbi.nlm.nih.gov/pubmed/28950442 }}$ \\
\hline DOI & $10.1111 /$ jmwh.12650
\end{tabular}

This is a NIVEL certified Post Print, more info at http://www.nivel.eu

\title{
Development of the Optimality Index-NL2015, an Instrument to Measure Outcomes of Maternity
} Care

Hermus, M., Boesveld, I., PAL-DE Bruin, K.M. VAN DER, WIEGERS, T.

\begin{abstract}
Introduction: An optimality index is a composite tool to measure maximum outcome with minimal intervention. It focuses on optimality instead of on normality and is useful in comparing differences in processes and perinatal outcomes for women at low risk of complications. The latest Dutch version dates from 2 decades ago, and international versions of the optimality index are not directly applicable to the Dutch maternity system. Most data for perinatal research in the Netherlands are derived from a national perinatal database: the Netherlands Perinatal Registry. The aim of this study was to develop a new Dutch version of the optimality index (OI-NL2015) that could be calculated from data derived from this national perinatal database and to assess the reliability of these data for use in the index.

Methods: Potential items were collected by a thorough comparison of earlier (inter)national optimality indexes and the current data collection of the national database. All items were reviewed by 2 experts in maternity care and assessed for importance, relevance for the Dutch maternity care system, and feasibility to retrieve information on these items. For each item a criterion for optimality was formulated based on evidence-based or consensus-based effectiveness of care in pregnancy and childbirth. All selected items were scored on potential problems, with reliability by 20 randomly selected community midwives. The level of agreement was calculated comparing these 2 data sets, which included data of the same women.

Results: The final OI-NL2015 consists of 31 items in 3 different components: 22 intrapartum, 7 neonatal, and 2 postpartum. Of the 7 items that were examined because of expected potential problems with reliability, in 6 items a level of 90\% agreement was found.

Discussion: An optimality index is not a standard measurement instrument but must be validated and adapted to local circumstances and available data.
\end{abstract}


Hermus, M., Boesveld, I., Pal-de Bruin, K.M. van der, Wiegers, T. Development of the optimality index-NL2015, an instrument to measure outcomes of maternity care. Journal of Midwifery \& Women's Health: 2017, 62(5), 580-588

\section{INTRODUCTION}

One of the hallmarks of midwifery philosophy is the "advocacy of nonintervention in the absence of complications." In line with this philosophy, labor and birth in women at low risk of perinatal complications are seen as physiologic events that do not require technologic or obstetric interventions unless indicated by a change in risk status. ${ }^{2}$ To evaluate maternity care in these women it is therefore preferable not to focus on perinatal complications and adverse outcomes as these are rare conditions in this population. Nonetheless, such variables are often the main outcome measures used when comparing maternity care outcomes among subgroups, such as women with different planned places of birth in the Netherlands. ${ }^{3-7}$ In addition, adverse outcomes may vary from mild to severe, and they rarely occur alone.

In 1980 Prechtl introduced another approach. He defined a list of criteria of the most favorable and optimal conditions for a representative and comprehensive description of the pre- and perinatal condition of the woman, the fetus, and the placenta. ${ }^{8}$ This list was based on common clinical experience and on perinatal mortality data. Applying this optimality concept, a list of maternal and newborn optimality criteria was designed. Wiegers updated and adapted this instrument in the early $1990 \mathrm{~s}^{9}$; later, it was revised and validated for use in the United States (the Optimality Index-US ${ }^{1,10}$, ${ }^{11}$ ) and in the United Kingdom (Optimality Index-UK). ${ }^{12}$

The Optimality Index (OI) is a composite outcome tool based on the concept of optimality. ${ }^{13}$ Optimality differs from normality because it avoids the problem of choosing a cutoff point on an often continuous scale of what is normal and what is not. In health care, normal is often defined as "without abnormalities" or "with the highest occurrence." This does not automatically mean that a normal process or outcome is the most optimal one. For instance, when the majority of women receive labor induction, that may be normal, but based on our knowledge of the physiology of labor and birth, it is not an optimal outcome. The OI combines commonly used perinatal outcomes, such as instrumental birth, birth weight, and perinatal death, with evidence-based processes, such as amniotomy, episiotomy, and the use of oxytocin for augmentation of labor, within one instrument. All items are scored optimal (1) or nonoptimal (0). Individual items within the OI are not weighted, because the instrument as a whole is self-weighting: it reflects the potential cascade of interventions by including items that are closely related. Although an individual sum score is calculated for each woman, the OI is more specifically designed to compare between groups. It can highlight differences in the total of processes and outcomes of care by showing the mean sum scores of optimally scored items within essentially healthy groups of pregnant women in whom adverse outcomes are rare. ${ }^{1}$ The OI has been shown to be valuable over a decade of meaningful use in distinguishing processes of maternity care across and within various groups. ${ }^{14}$

\section{Quick Points}

An optimality index is an outcome measurement tool that focuses on optimal maternity care outcomes instead of the presence of perinatal complications. 
Hermus, M., Boesveld, I., Pal-de Bruin, K.M. van der, Wiegers, T. Development of the optimality index-NL2015, an instrument to measure outcomes of maternity care. Journal of Midwifery \& Women's Health: 2017, 62(5), 580-588

A current version of the Dutch Optimality Index (OI-NL2015) has been developed to measure differences between groups of low-risk women by comparing a sum score of optimal process and outcome items in perinatal care.

$\checkmark$ Twenty-nine of these 31 items are evidence based and 2 are consensus based, and all items except one can be derived reliably from the Dutch national perinatal registry.

An optimality index is not a standard measurement instrument to be translated and used in a different setting, but must be validated and adapted to local circumstances and available data.

Although there is much overlap in the different versions of the OI, all versions include items that are applicable only to a specific health care system or available from a specific perinatal database. In the Netherlands, most data for perinatal research are obtained from a national perinatal database: the Netherlands Perinatal Registry. ${ }^{15}$ The latest Dutch version of the OI, also partly based on this registry, dates from 2 decades ago. ${ }^{9}$ In 2013, a national study was started to evaluate the effects of planned birth center birth in the Netherlands compared to alternative places to give birth (the Dutch Birth Centre Study). ${ }^{16}$ To be able to use the OI in the current Netherlands practice climate and to use the OI as the primary outcome of the Dutch Birth Centre study, an updated version was needed.

The aim of this study was to develop a new version of the optimality index (OINL2015) based exclusively on the items in the Netherlands Perinatal Registry, as an outcome measurement tool for women with term pregnancies and at low risk for perinatal complications who were under the care of a midwife at the onset of labor. We also investigated the reliability of the items of the OI-NL2015 within the Netherlands Perinatal Registry. The resulting OI-NL2015 will be used in the Dutch Birth Centre Study. ${ }^{16}$

\section{METHODS}

\section{Setting}

The Dutch maternity care system is based on the notion that pregnancy, birth, and the puerperium are primarily physiologic processes. Most pregnant women are initially considered as low risk, and in $2015,87 \%$ of them initially received antenatal care from an independently practicing community midwife. A woman is referred to secondary care if risk factors arise during pregnancy, during labor, or in the postpartum period. Secondary care is provided under the responsibility of an obstetrician, and clinical midwives or trainee obstetricians can be involved. This risk selection and role division between the professions is based on the List of Obstetric Indications, a document that designates the appropriate level of care for more than a hundred obstetric conditions. This list recommends that only women without known risk factors for complications in pregnancy and childbirth are under the care of a community midwife. ${ }^{17,18}$ Other conditions for this type of care are prepregnancy body mass index below 40 and spontaneous start of labor. Women with (previous) obstetric complications (eg, cesarean at prior birth, preterm contractions) or whose labor is induced are at the onset of labor under the care of the obstetrician. 
Hermus, M., Boesveld, I., Pal-de Bruin, K.M. van der, Wiegers, T. Development of the optimality index-NL2015, an instrument to measure outcomes of maternity care. Journal of Midwifery \& Women's Health: 2017, 62(5), 580-588

Interventions such as augmentation of labor, pharmacologic pain relief, continuous fetal monitoring, or instrumental birth take place only in secondary or tertiary care. In $2015,51.4 \%$ of all women who gave birth in the Netherlands were in primary community midwife-led care at the onset of labor. ${ }^{19}$

\section{Construction of the Index}

An optimality index is not a static measurement tool. It requires close evaluation of its internal validity before it can be applied to specific situations in practice. The tool needs to be critically assessed and redesigned on a regular basis to accommodate different or changed insights into maternity care and to be appropriate for the available data and the purpose of the study. ${ }^{9}$

To develop the new Dutch version of the index, several steps were taken, all by 2 researchers (TW and MH). First, we collected and sorted all possible items already used in the existing optimality indexes: the Perinatal Background Index and Perinatal Outcome Index (PBI and POI, both elements of the previous Dutch OI, 36 items), the Optimality Index-US (OI-US, 94 items), and the Optimality Index-UK (OI-UK, 54 items). ${ }^{9,11,12}$

Second, the current list of items as registered in the Netherlands Perinatal Registry was studied to find potential extra items for the OI-NL2015. The Netherlands Perinatal Registry is an electronically collected national database that contains individual demographics and risk factors, as well as prenatal, intrapartum, postpartum, and neonatal interventions and outcomes during the first 7 days after birth. It is a routine registry in which standard response categories are defined for each item. There are no open-ended questions. The respondent has to score multiple discrete choices per item. However, completing each item is not required for all items. ${ }^{20}$ All 4 professional maternity care disciplines (midwives, general practitioners, obstetricians, pediatricians) have their own professional registry. These separate registries are afterwards linked to each other into one combined file per woman, with data obtained from all involved professionals. Not all items from the 4 registries are scored for all women, as not all 4 professionals are involved in caring for each woman. ${ }^{21}$ Reliability of individual items of this database has been studied before, but information about the interrater agreement of more than one item of the database is rare. ${ }^{22,23}$

Third, all potential items retrieved from the first 2 steps were reviewed by the same 2 researchers and evaluated for their relevancy to the Dutch maternity care system and the availability of information on this item within the Netherlands Perinatal Registry. Fourth, items were excluded if they did not identify women at low risk of complications at the onset of labor under the care of a midwife according to criteria written in the List of Obstetric Indications. ${ }^{17}$

Fifth, the optimal evidence-based value for an item was decided. This was based on the evidence lists about the optimal value of the items of the 3 earlier versions of the optimality indexes as well as the recently updated guideline from the English National Institute for Health and Care Excellence (NICE) on the subject of intrapartum care. ${ }^{9,11,12,24}$ If no evidence was found in one of these previously mentioned documents, a search was conducted in the PubMed database. Clinical consensus was defined as evidence if no scientific research with evidence for optimality was found, but national guidelines contained uniform endorsement of the desirability of an outcome. The term clinical consensus was also used when the criteria for optimality were adapted from the existing categorical options in the 
Hermus, M., Boesveld, I., Pal-de Bruin, K.M. van der, Wiegers, T. Development of the optimality index-NL2015, an instrument to measure outcomes of maternity care. Journal of Midwifery \& Women's Health: 2017, 62(5), 580-588

Netherlands Perinatal Registry. For instance, in the Netherlands Perinatal Registry, the item "duration of first stage of labor" is categorically scored, with values less than 6, 6 to 12, and greater than 12 hours. An individual item was recorded in the OINL2015 if its criterion for optimality was agreed on by both experts (TW and MH). These methods (a thorough comparison of earlier versions of the Optimality Index, deriving consensus about the inclusion of all items, and coming to agreement on the criteria for an optimal score) provided data to support the content validity of the index. This is consistent with the current recommendations for the construction of assessment instruments. ${ }^{25}$

\section{Reliability}

To study the reliability of the data extracted from the Netherlands Perinatal Registry, we asked 20 community midwives to assess all potential items of the OI-NL2015 as to their perceptions of the level of accuracy of these items in the registry. The midwives were randomly chosen from a group of 52 midwives all working in one area located around a hospital in the southern part of the Netherlands. They represented 12 different midwifery practices; all had worked more than 5 years as a primary community midwife and had more than 5 years of experience in filling out data in the registry. The midwives were asked to give their opinion on the reliability of the registry per item on a rating scale of 4 points: 1 (very unsure about the reliability) to 4 (very sure about the reliability). For example, would "artificial rupture of membranes" be reliably recorded in the Netherlands Perinatal Registry? An item was assessed as unsure if more than $30 \%$ of the respondents answered "unsure" or "very unsure."

In order to assess the reliability of these data, all unsure items were added to a case report form that was used to collect data for the Dutch Birth Centre study. This cohort consisted of 3455 low-risk women who started labor under the care of a community midwife (Marieke Hermus, RM, MSc, unpublished data, February 2017); the methodology for the Dutch Birth Centre study has been reported elsewhere. ${ }^{16}$ It was assumed that the remaining items were reliably registered within the registry. The same person filled out both data sets directly after birth, sometimes completed by a colleague if there was additional information on outcomes or interventions at a later stage.

All women in the Dutch Birth Centre Study were linked to their data in the Netherlands Perinatal Registry. This resulted in a combined database in which all unsure items were recorded twice per woman: once in the Dutch Birth Centre Study and once in the national perinatal registry. Missing data were recoded when possible with extrapolated data; for example, if data about referral were missing but the woman had a cesarean birth, referral was assumed to have taken place and was therefore recoded from missing to referred.

For all items, and corresponding to other optimality indexes, each optimal item received a score of 1 and each nonoptimal item received a score of $0 .^{26}$ To determine the reliability of the unsure items, we compared the percentage of women with an optimal score on an item between our study data and the data derived from the national perinatal registry. Agreement was defined as the frequency with which 2 evaluators assigned the exact same rating. ${ }^{27}$ Ninety percent absolute agreement was used as an acceptable level of agreement. ${ }^{28}$

The Netherlands Perinatal Registry gave approval for anonymous use of requested data for the analyses of this study. Design and planning of the study were presented 
Hermus, M., Boesveld, I., Pal-de Bruin, K.M. van der, Wiegers, T. Development of the optimality index-NL2015, an instrument to measure outcomes of maternity care. Journal of Midwifery \& Women's Health: 2017, 62(5), 580-588

to the Medical Ethics Committee of the University Medical Centre Utrecht. They confirmed that this study agrees with Dutch legal regulations for the methods used for this study. For this reason, official ethical approval of this study was not required. ${ }^{29}$

\section{RESULTS}

In total, 94 possible OI items were described in the 3 earlier versions of the OI, and 6 possible new items were derived from the Netherlands Perinatal Registry (Figure ${ }^{1}$ ). From these 100 items, 46 items were not in the Netherlands Perinatal Registry and therefore excluded. Another 11 items were present in the registry but only for a subgroup of women, namely, those under the care of an obstetrician after referral during labor. Including these items would have led to missing values for nonreferred women, so exclusion was the only option. Nine items were not distinctive for women at low risk of complications starting labor under the care of a community midwife, according to the List of Obstetric Indications. ${ }^{17}$ These items included women with problems like hypertension, diabetes, previous problems during childbirth (such as a previous cesarean), or an indication for induction of labor. If any of these events occur, a woman is no longer considered as low risk and will be referred to secondary care before onset of labor. A list of the excluded items is in Appendix Appendix 1.

\section{[FIGURE 1]}

Flowchart on Selection of Items for Optimality Index-NL2015

Table ${ }^{1}$ shows the final selection of 31 items for the OI-NL2015 with the criteria for optimality and the maternal characteristics to adjust the sum score. As shown in this table, 4 items did not appear in earlier versions of the OI. These items are "serious maternal complications postpartum," "manual placenta removal," "urgent referral," and "cephalic position at birth."

\section{[TABLE 1]}

Four maternal characteristics were used to adjust the sum score of the OI-NL2015 for potential selection bias. Three of them were used in earlier versions of the OI (maternal age, maternal ethnic background, and social deprivation). The fourth item, "social deprivation," was indirectly measurable by linking the postal code as registered in the Netherlands Perinatal Registry to the database of the Netherlands Institute for Social Research. ${ }^{30}$ The postal code also made it possible to extend the number of maternal characteristics to 4 by linking it to the database of Statistics Netherlands to gain information on the level of urbanization. ${ }^{31}$ Both procedures are often used in research with data obtained from the Netherlands Perinatal Registry. Evidence for a criterion of optimality was found in earlier versions of optimality indexes in 25 items of the 31 potential items left. This was consistent with the evidence obtained in the recently updated NICE intrapartum guideline. ${ }^{24}$ Evidence for the 4 new items (see Table ${ }^{1}$ ) was found in this guideline as well, except for the criterion "no urgent referral." Criteria for this item were adapted as suggested in the referral categories by Amelink et al. ${ }^{32}$ For the criterion for the item "time between rupture of membranes and birth," the List of Obstetric Indications was used as evidence. ${ }^{17}$ For the item "duration of first stage," it was only possible to record 0 to 6 hours, 6 to 12 hours, or 12 or more hours in the perinatal registry. ${ }^{15}$ Therefore, a 
Hermus, M., Boesveld, I., Pal-de Bruin, K.M. van der, Wiegers, T. Development of the optimality index-NL2015, an instrument to measure outcomes of maternity care. Journal of Midwifery \& Women's Health: 2017, 62(5), 580-588

maximum of 12 hours was chosen to be the criterion for optimality. The criteria for "congenital anomalies" were adapted from the European Registration of Congenital Anomalies (and Twins) that was used in earlier Dutch research on congenital anomalies. $^{33,34}$

The final OI-NL2015 consists of a list of 31 items in 3 different components: 22 intrapartum, 7 neonatal, and 2 postpartum.

All 31 items were presented to 20 randomly chosen community midwives and scored on expected reliability in the Netherlands Perinatal Registry. Seven items scored were considered unsure or very unsure. These items were added to the case report form of the Dutch Birth Centre Study in order to study the interrater agreement on the optimality score between both registrations.

As shown in Table ${ }^{2}, 6$ of the 7 OI-NL2015 unsure items scored more than $90 \%$ agreement within both databases. The agreement on the OI item "birth occurred in the place originally intended at the onset of labor" was the lowest; this was the case in $71.8 \%$.

[TABLE 2]

\section{DISCUSSION}

The OI-NL2015 is designed to assess aggregated outcomes in comparison to an evidence-based standard and has its value in distinguishing processes of maternity care across various groups, as has been demonstrated in other publications. ${ }^{1,14}$ To our knowledge this is the first outcome measurement tool that focuses on optimality and can be calculated with data from the Netherlands Perinatal Registry. As is true of other versions of the Optimality Index, it is intended as a research instrument, not a quality assessment tool.

The OI-NL2015 consists of 31 items in 3 different components: 22 intrapartum, 7 neonatal, and 2 postpartum items. For 29 items of the OI-NL2015, scientific evidence was found for its criteria of optimality. For 2 items, this criterion was based on consensus. Thirty out of all 31 items of the OI-NL2015 can reliably be used when calculating a sum score for the OI-NL2015 with data from the Netherlands Perinatal Registry.

To use the OI-NL2015, all items need to be scored optimal (1) or nonoptimal (0), as is true of other forms of the optimality index. To use this index, inclusion criteria for the sample are women with a term pregnancy who are at low risk of complications and under the care of a community midwife at the onset of labor. A mean sum optimality score should be calculated for each group being evaluated; this must be adjusted for the baseline characteristics of maternal background, maternal age at the time of birth, socioeconomic status, and level of urbanization. Because of the large differences in frequencies of interventions and outcomes between nulliparous and multiparous women, groups should also be analyzed by parity. ${ }^{35}$

More items are known to have an effect on optimal outcome than the items now included in the OI-NL2015. For the development of the OI-NL2015 we only had the items registered in the Netherlands Perinatal Registry available. Therefore, other items such as body mass index, smoking behavior, continuous support during labor, and skin-to-skin contact between the mother and her newborn directly after birth could not be included, although they are known to have evidence-based effects on 
Hermus, M., Boesveld, I., Pal-de Bruin, K.M. van der, Wiegers, T. Development of the optimality index-NL2015, an instrument to measure outcomes of maternity care. Journal of Midwifery \& Women's Health: 2017, 62(5), 580-588

optimal outcomes. To use the OI-NL2015 in future studies, all 31 items should be reevaluated when major changes in maternity care have occurred or when there are changes in items included in the Netherlands Perinatal Registry.

Data in perinatal registries are routinely collected and often used in scientific research, although little is known about their reliability and validity. The degree of underreporting and the percentage of incorrect data have an unknown effect. ${ }^{20} \mathrm{We}$ therefore assessed the reliability of all items to be used in the OI-NL2015. All but one scored more than $90 \%$ agreement between the data from Netherlands Perinatal Registry and from the Dutch Birth Centre Study. The item that did not meet the $90 \%$ criterion was "birth occurred in the planned place of birth." The relatively high percentage of women with unknown planned place of birth in the registry and the lack of definition of what birth location is called a birth center could have contributed to that. ${ }^{16,36}$ When using the OI-NL2015 only with data derived from registry and not being able to assess the item "birth occurred in the planned place of birth" in another way, one should be alert that the sum score of the OI-NL2015 will end up lower, implying a lower level of optimality.

Although the OI-NL2015 is a research instrument, it can be used in care to increase awareness of the effect of interventions that are used on a daily basis in some midwifery practices (eg, episiotomy): it can demonstrate differences in the process between comparable subgroups by showing that every (unnecessary) intervention interrupts the process of physiologic childbirth and often starts a cascade of other interventions. Evaluation and adjustment of these processes can lead to more optimal outcomes. Awareness of differences between one subgroup and another can be the first step to change practice. Although the aggregated evaluation provides information on processes, the $\mathrm{OI}$ is not an alternative for the evaluation of care on a case level. It is supplementary. Acquaintance with the OI-NL2015 can also lead to a more positive evidence-based approach to childbirth by looking at sum scores of optimal items instead of the percentage of rare adverse outcomes (eg, perinatal death).

For this study, the aim was to develop a new Dutch version of the Optimality Index that can be calculated with data from the Netherlands Perinatal Registry and could be used as an outcome measurement tool for the Dutch Birth Centre Study. ${ }^{16}$ The perinatal registry includes more than $95 \%$ of all births in the Netherlands, and data are supplied by 3 different disciplines, all involved in maternity care. Data are generated per hospital department (obstetrics and/or neonatology) and per independent community midwifery practice. With their own identification code, midwifery practices are able to look at their own data on maternity care processes and outcomes in relation to anonymized national data online. In the near future, it would be helpful if the OI-NL2015 could be included as an automatically generated outcome score within this web-based program to make it easier to reflect on the given care. ${ }^{37}$ Although it is clear that in clinical use an optimality list should never replace the separate recordings of complications and was never intended to do so, a new version of the Optimality Index ensures a more comprehensive evaluation of potential differences between subgroups of low-risk women at the onset of labor under the care of a community midwife, divided by planned place of birth (ie, home, hospital, birth center). ${ }^{8}$ 
Hermus, M., Boesveld, I., Pal-de Bruin, K.M. van der, Wiegers, T. Development of the optimality index-NL2015, an instrument to measure outcomes of maternity care. Journal of Midwifery \& Women's Health: 2017, 62(5), 580-588

\section{CONCLUSION}

We redeveloped and updated an outcome measurement tool that focuses on optimal outcomes instead of the presence of perinatal complications. All but one met the $90 \%$ criterion of reliability to use when calculating a sum score with data from the Netherlands Perinatal Registry. The Optimality Index NL2015 will be used to distinguish variation between groups of low-risk women by planned place of birth as studied in the Dutch Birth Centre study. An optimality index is not a standard measurement instrument but must be validated and adapted to local circumstances and available data.

\section{CONFLICT OF INTEREST}

The authors have no conflicts of interest to disclose.

\section{ACKNOWLEDGMENTS}

This study received funding from ZonMW (the Netherlands Organisation for Health Research and Development) in the context of the research program Pregnancy and Childbirth, grant number 209020012. We thank all participating midwives for filling out the case report forms of the Dutch Birth Centre study. We also thank Paula van Dommelen and Nathalie Masurel for making linkage to other databases possible. Perined gave permission to use the registry data and assisted the researchers in dealing with data from the Netherlands Perinatal Registry.

\section{Appendix 1: Items From Other Optimality Indexes That Were Not Included in the Optimality Index-NL2015 and Reason for Exclusion}

\begin{tabular}{|l||}
\hline Not possible to register in Netherlands Perinatal Registry $(\mathbf{n}=\mathbf{4 6})$ \\
\hline \hline Marital status \\
\hline Took part of parenthood classes \\
\hline Use of any smoking since conception (during index pregnancy) \\
\hline Use of any alcohol since conception (during index pregnancy) \\
\hline \hline Prescription drugs or over-the-counter medications since conception \\
\hline Prepregnancy body mass index $(18.5-24.9)^{\text {a }}$ \\
\hline \hline Access to services (woman speaks and understands Dutch) \\
\hline Previous preterm birth < 28 wks \\
\hline Previous preterm birth 28-36 wks \\
\hline Previous instrumental birth \\
\hline \hline Previous low-birth-weight-for-gestation newborn \\
\hline Previous infertility \\
\hline \hline Uncertain date of last menstrual period \\
\hline Intrauterine fetal demise \\
\hline History of intimate partner violence during the pregnancy \\
\hline \hline Anemia (Hb < 6.8 mmol/L) \\
\hline $\begin{array}{l}\text { Major psychiatric history (formal diagnosis or treated with drugs or inpatient } \\
\text { therapy) }\end{array}$ \\
\hline \hline
\end{tabular}


Hermus, M., Boesveld, I., Pal-de Bruin, K.M. van der, Wiegers, T. Development of the optimality index-NL2015, an instrument to measure outcomes of maternity care. Journal of Midwifery \& Women's Health: 2017, 62(5), 580-588

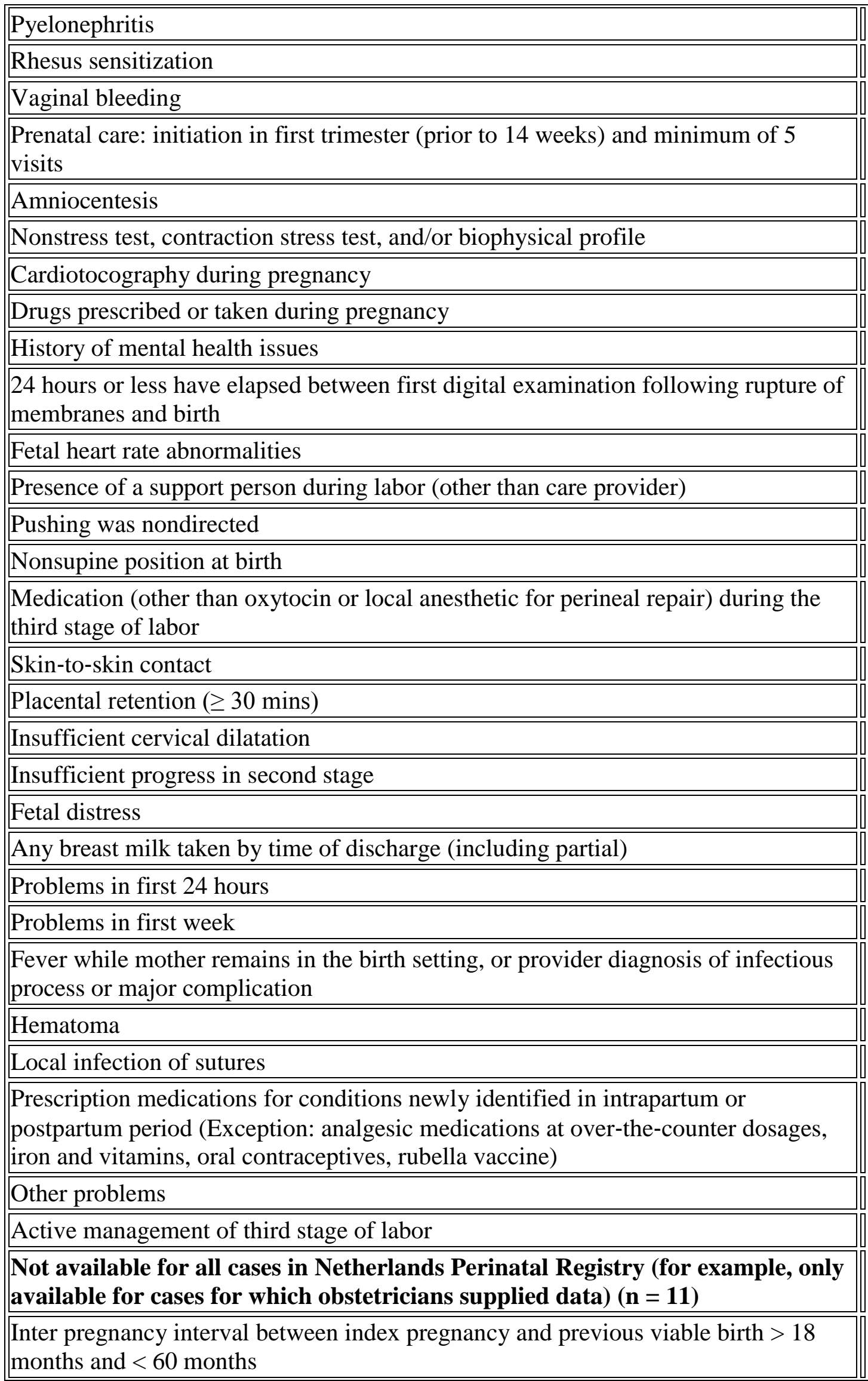


Hermus, M., Boesveld, I., Pal-de Bruin, K.M. van der, Wiegers, T. Development of the optimality index-NL2015, an instrument to measure outcomes of maternity care. Journal of Midwifery \& Women's Health: 2017, 62(5), 580-588

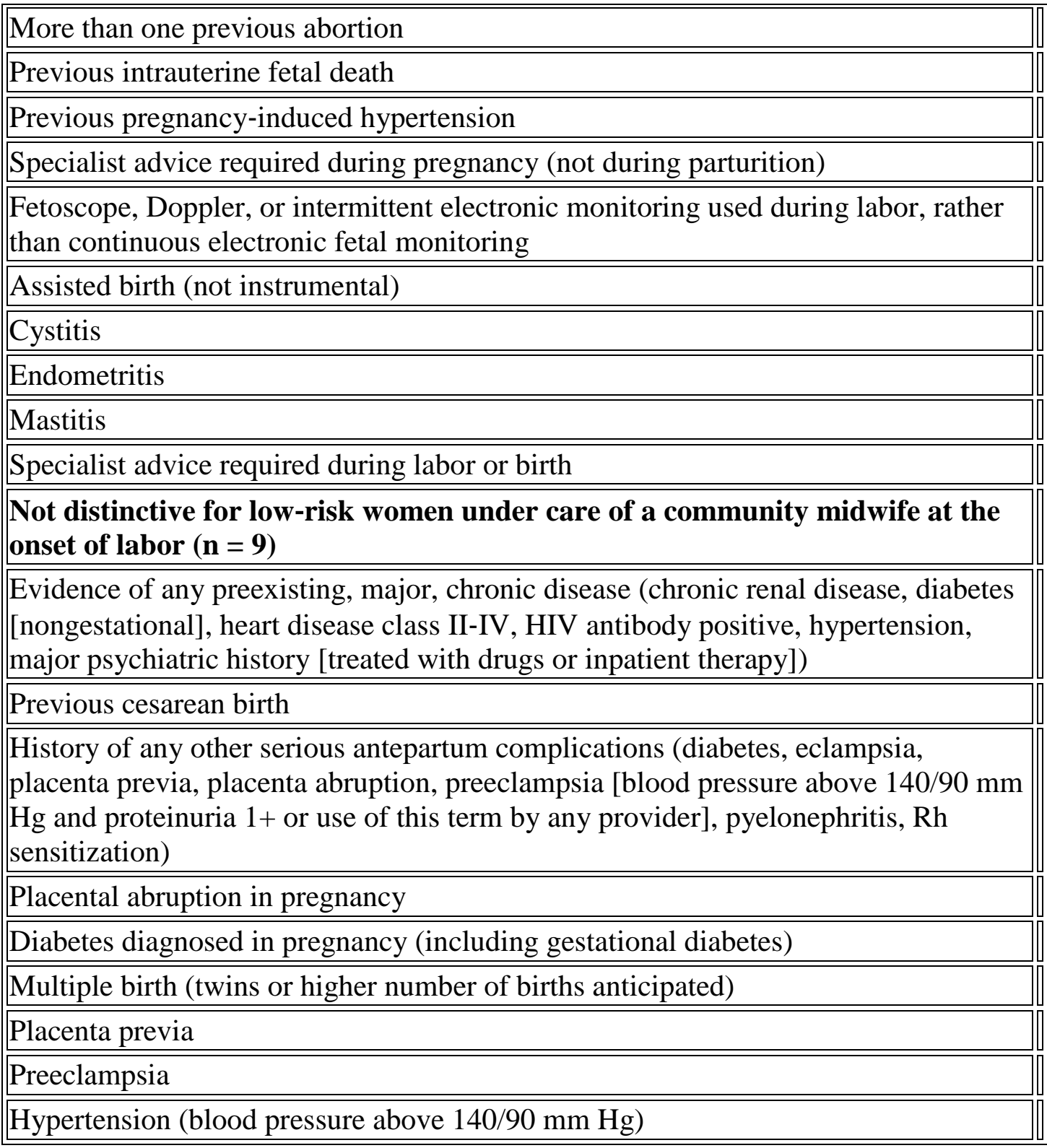

- All items above were included in at least one of the other optimality indexes ${ }^{1,}$ 9,12

- $\quad$ abody mass index $=$ weight $[\mathrm{in} \mathrm{kg}] /$ height $\left[\right.$ in $\left.\mathrm{m}^{2}\right]$

\section{Biographies}

- Marieke Hermus, RM, MSc, is a PhD student at Leiden University Medical Center, the Netherlands, and a junior researcher at the Netherlands Organisation for Applied Scientific Research (TNO). She practices as a community midwife in Oosterhout, the Netherlands.

- Inge Boesveld, MSc, is a midwife (n.p.) who is a PhD student at University Medical Centre Utrecht, the Netherlands. She is a manager at Jan van Es Institute (Netherlands Expert Centre for Integrated Primary Care). 
Hermus, M., Boesveld, I., Pal-de Bruin, K.M. van der, Wiegers, T. Development of the optimality index-NL2015, an instrument to measure outcomes of maternity care. Journal of Midwifery \& Women's Health: 2017, 62(5), 580-588

- Karin van der Pal-de Bruin, $\mathrm{PhD}$, worked as a perinatal epidemiologist and team coordinator at the Netherlands Organisation for Applied Scientific Research (TNO) and is an assistant professor at the Department of Medical Statistics and Bioinformatics at Leiden University Medical Center, the Netherlands.

- Therese Wiegers, $\mathrm{PhD}$, is a senior researcher and program coordinator for maternity care and reproductive health at the Netherlands Institute for Health Services Research (NIVEL) in Utrecht, the Netherlands. 
Hermus, M., Boesveld, I., Pal-de Bruin, K.M. van der, Wiegers, T. Development of the optimality index-NL2015, an instrument to measure outcomes of maternity care. Journal of Midwifery \& Women's Health: 2017, 62(5), 580-588

\section{REFERENCES}

1.Murphy PA, Fullerton JT. Measuring outcomes of midwifery care: development of an instrument to assess optimality. J Midwifery Womens Health. 2001;46(5):274-284. http://www.ncbi.nlm.nih.gov/pubmed/11725898.

2. Yucel C, Taskin L, Low LK. Validity and reliability of the Turkish version of the Optimality Index-US (OI-US) to assess maternity care outcomes. Midwifery. 2015;31(12):1135-1142. https://doi.org/10.1016/j.midw.2015.08.003.

3.De Jonge A, Van Der Goes BY, Ravelli ACJ, et al. Perinatal mortality and morbidity in a nationwide cohort of 529688 low-risk planned home and hospital births. BJOG. 2009;116(9):1177-1184. https://doi.org/10.1111/j.1471-0528.2009.02175.x.

4.Offerhaus PM, HukkelhovenCWPM,de JongeA, van der Pal-de Bruin KM, Scheepers PLH, Lagro-Janssen ALM. Persisting rise in referrals during labor in primary midwife-led care in the Netherlands. Birth. 2013;40(3):192-201. https://doi.org/10.1111/birt.12055.

5.Wiegers TA, Keirse MJ, van der Zee J, Berghs GA. Outcome of planned home and planned hospital births in low risk pregnancies: prospective study in midwifery practices in the Netherlands. BMJ. 1996;313(7068):1309-1313. https://doi.org/10.1136/bmj.313.7068.1309.

6.Amelink-Verburg MP, Rijnders MEB, Buitendijk SE. A trend analysis in referrals during pregnancy and labour in Dutch midwifery care 1988-2004. BJOG. 2009;116(7):923-932. https://doi.org/10.1111/j.1471-0528.2009.02202.x.

7.Evers ACC, Brouwers HAA, Hukkelhoven CWPM, et al. Perinatal mortality and severe morbidity in low and high risk term pregnancies in the Netherlands: prospective cohort study. BMJ. 2010;341:c5639. https://doi.org/10.1136/bmj.c5639.

8.Prechtl HF. The optimality concept. Early Hum Dev. 1980;4(3):201-205. http://www.ncbi.nlm.nih.gov/pubmed/7418634. Accessed March 25, 2016.

9.Wiegers TA, Keirse MJ, Berghs GA, van der Zee J. An approach to measuring quality of midwifery care. J Clin Epidemiol. 1996;49(3):319-325. http://www.ncbi.nlm.nih.gov/pubmed/8676180.

10.Low LK, Seng JS, Miller JM. Use of the Optimality Index- United States in perinatal clinical research: a validation study. J Midwifery Womens Health. 2008;53(4):302-309. https://doi.org/10.1016/j.jmwh.2008.01.009.

11. Low LK, Miller J. A clinical evaluation of evidence-based maternity care using the Optimality Index. J Obstet Gynecol Neonatal Nurs. 2006;35(6):786-793. https://doi.org/10.1111/j.1552-6909.2006.00107.x.

12.Sheridan M, Sandall J. Measuring the best outcome for the least intervention: can the Optimality Index-US be applied in the UK? Midwifery. 2010;26(6):e9-15. https://doi.org/10.1016/j.midw.2009.09.002 .

13. Kennedy HP. A concept analysis of optimality in perinatal health. J Obstet Gynecol Neonatal Nurs. 2006;35(6):763-769. https://doi.org/10.1111/j.1552-6909.2006.00104.x.

14.Fullerton J, Low L. Measurement of perinatal outcomes: a decade of experience and a future vision for the Optimality Index-US. Int J Childbirth. 2011;1(3):171-178.

15.Perined. https://www.perined.nl/. Accessed April 25, 2016.

16. Hermus MAA, Wiegers TA, Hitzert MF, et al. The Dutch Birth Centre Study: study design of a programmatic evaluation of the effect of birth centre care in the Netherlands. BMC Pregnancy Childbirth. 2015;15(1):148. https://doi.org/10.1186/s12884-015-0585-1.

17.College voor Zorgverzekeringen. Verloskundig Vademecum. Eindrapport van de Commissie Verloskunde van Het College Voor Obstetric Working Group of the National Health Insurance Board CVZ]. Diemen: CVZ; 2003.

18.Amelink-Verburg MP, Buitendijk SE. Pregnancy and labour in the Dutch maternity care system: what is normal? The role division between midwives and obstetricians. J Midwifery Womens Health. 2010;55(3):216-225. https://doi.org/10.1016/j.jmwh.2010.01.001.

19.Perined. Perinatale Zorg in Nederland 2015. Utrecht: Perined; 2016.

20.Anthony S. The Dutch Perinatal and Neonatal Registers: Applications in Perinatal Epidemiology. 2005.

21.Stichting Perinatal Registratie Nederland. Perinatale Zorg in Nederland 2013. [Perinatal care in the Netherlands]. Utrecht: the Netherlands Perinatal Registry; 2014.

22.Elferink-Stinkens PM, Brand R, Verloove-Vanhorick SP, van Hemel OJS.

Onderrapportage van de eersteweeksterfte bij vroeggeboorte in de Landelijke Verloskunde 
Hermus, M., Boesveld, I., Pal-de Bruin, K.M. van der, Wiegers, T. Development of the optimality index-NL2015, an instrument to measure outcomes of maternity care. Journal of Midwifery \& Women's Health: 2017, 62(5), 580-588

Registratie. [Under reporting of the first week of death at premature childbirth in the Netherlands Perinatal Registry] Ned Tijdschr Geneeskd. 1993;137:298-301.

23. Haring M. Onderzoek Naar de Betrouwbaarheid van de LVR1 En LVR 2. Eindrapport [Research on the reliability of the RHINELAND REGIONAL COUNCIL LVR1 and 2. Final report]. Utrecht: SIG Zorginformatie; 1996.

24.NICE. Intrapartum Care. Care of Healthy Women and their Babies During Childbirth. NICE Clinical Guidelines. London: NICE; 2014.

25.Polit DF, Beck CT. Nursing Research: Generating and Assessing Evidence for Nursing Practice. Philadelphia: Wolters Kluwer Health/LippincottWilliams \&Wilkins; 2012.

26.Murphy PA, Fullerton JT. Codebook Optimality Index-US 2012.

http://www.midwife.org/Optimality-Index-US. Published 2012. Accessed July 16, 2014.

27.GrahamM, Milanowski A, Miller J.Measuring and Promoting Inter-Rater Agreement of

Teacher and Principal Performance Ratings.Washington, DC: Center for Educator

Compensation Reform; 2012.

28. Hartmann DP. Considerations in the choice of interobserver reliability estimates. J Appl Behav Anal. 1977;10(1):103-116. https://doi.org/10.1901/jaba.1977.10-103.

29.CCMO (central committee on research involving human subjects).

http://www.ccmo.nl/en/ccmo-directives. Accessed July 8, 2015.

30.SCP. Statusscores 2014 SCP.

https://www.scp.nl/FAQ/Onderzoek/Kan_ik_statusscores_opvragen. Published 2014.

Accessed April 30, 2015.

31.CBS. Statistics Netherlands. www.cbs.nl. Published 2014. Accessed April 12, 2015.

32.Amelink-Verburg MP, Verloove-Vanhorick SP, Hakkenberg RMA, Veldhuijzen IME,

Bennebroek Gravenhorst J, Buitendijk SE. Evaluation of 280000 cases in Dutch midwifery practices: a descriptive study. BJOG. 2008;115(5):570-578. https://doi.org/10.1111/j.14710528.2007.01580.x.

33.Mohangoo AD, Pal-de Bruin van der KM, Buitendijk SE. Aangeboren Afwijkingen in Nederland 1997-2008. Gebaseerd Op de Landelijke Verloskunde En Neonatale Registraties [Birth Defects in 1997-2008 Netherlands. Based on the Rural Obstetrics and Neonatal Registrations]. Leiden: TNO; 2010.

34.European Registration of Congenital Anomalies (and Twins). http://www.eurocatnetwork.eu/. Accessed April 20, 2015.

35.Bai J, Wong FWS, Bauman A, Mohsin M. Parity and pregnancy outcomes. Am J Obstet Gynecol. 2002;186(2):274-278. http://www.ncbi.nlm.nih.gov/pubmed/11854649. Accessed November 13, 2016.

36. Offerhaus PM, de Jonge A, van der Pal-de Bruin KM, Hukkelhoven CWPM, Scheepers PLH, Lagro-Janssen ALM. Change in primary midwife-led care in the Netherlands in 20002008: A descriptive study of caesarean sections and other interventions among 789,795 low risk births. Midwifery. 2014;30(5):560-566. https://doi.org/10.1016/j.midw.2013.06.013. 37.Perined|Perined-Insight. https://www.perined.nl/producten/perinedinsight. Accessed February 20, 2017.

\section{FIGURES AND TABLES}

Table 1. Optimality Index NL 2015 With the Criteria for Optimality

\begin{tabular}{|l|l|}
\hline \multicolumn{1}{|c|}{ Optimality Index NL-2015 ${ }^{\mathrm{a}, \mathrm{b}}$} & $\begin{array}{c}\text { Criterion for } \\
\text { Optimality }\end{array}$ \\
\hline Intrapartum component & \\
\hline \hline Time between rupture of membranes and birth & $\leq 24 \mathrm{hrs}$ \\
\hline Duration of first stage of labor & $\leq 12 \mathrm{hrs}$ \\
\hline \hline Duration of second stage of labor & $\leq 120 \mathrm{~min}$ \\
\hline Color of amniotic fluid & Clear \\
\hline \hline Use of oxytocin for augmentation of labor & No \\
\hline
\end{tabular}


Hermus, M., Boesveld, I., Pal-de Bruin, K.M. van der, Wiegers, T. Development of the optimality index-NL2015, an instrument to measure outcomes of maternity care. Journal of Midwifery \& Women's Health: 2017, 62(5), 580-588

\begin{tabular}{|c|c|}
\hline Optimality Index NL-2015 a,b & $\begin{array}{l}\text { Criterion for } \\
\text { Optimality }\end{array}$ \\
\hline Amniotomy & No \\
\hline $\begin{array}{l}\text { Oral or injectable medication for pain relief during first or second stage of } \\
\text { labor }\end{array}$ & No \\
\hline Epidural analgesia for labor and/or birth & No \\
\hline Birth occurred in the place originally intended at the onset of labor & $\begin{array}{l}\text { Planned place of } \\
\text { birth is final place } \\
\text { of birth }\end{array}$ \\
\hline Fetal presentation at birth & Cephalic \\
\hline Cephalic position at birth ${ }^{\mathrm{c}}$ & Occipital \\
\hline Instrumental (vaginal) birth & No \\
\hline Cesarean & No \\
\hline Episiotomy & No \\
\hline $\begin{array}{l}\text { First- or second-degree laceration of perineum or perineal tissue requiring } \\
\text { sutures (including sulcus and cervical lacerations) }\end{array}$ & No \\
\hline $\begin{array}{l}\text { Third- or fourth-degree extension of either an episiotomy or a first- or } \\
\text { second-degree laceration }\end{array}$ & No \\
\hline Loss of blood during birth & $\angle 1000 \mathrm{~mL}$ \\
\hline Blood transfusion & No \\
\hline $\begin{array}{l}\text { Other serious intrapartum complications (eclampsia, preeclampsia, or } \\
\text { HELLP syndrome present during intrapartum period, placental abruption, } \\
\text { vasa previa, placenta previa discovered during intrapartum period, infected } \\
\text { uterus before birth, other major serious obstetric complications) }\end{array}$ & No \\
\hline Referral during labor or within 2 hours postpartum & No \\
\hline Urgent referral $^{\mathrm{c}}$ & No \\
\hline Manual placenta removal (after vaginal birth) ${ }^{\mathrm{c}}$ & No \\
\hline \multicolumn{2}{|l|}{ Neonatal component } \\
\hline Duration of gestation & $37-42$ weeks \\
\hline Birth weight & P10-P90 \\
\hline Apgar score at 5 minutes & $\geq 9$ \\
\hline Transfer to high-risk neonatal care setting within 24 hours postpartum & No \\
\hline Congenital anomalies & No \\
\hline $\begin{array}{l}\text { Birth trauma within } 24 \text { hours postpartum (Erb's palsy, clavicular fracture, } \\
\text { cephalo-hematoma, other serious birth trauma) }\end{array}$ & No \\
\hline Perinatal death within 24 hours postpartum & No \\
\hline \multicolumn{2}{|l|}{ Postpartum component } \\
\hline Maternal mortality within 24 hours after birth & No \\
\hline Serious maternal postpartum complications (eclampsia, deep venous & No \\
\hline
\end{tabular}


Hermus, M., Boesveld, I., Pal-de Bruin, K.M. van der, Wiegers, T. Development of the optimality index-NL2015, an instrument to measure outcomes of maternity care. Journal of Midwifery \& Women's Health: 2017, 62(5), 580-588

\begin{tabular}{||c|c|}
\hline \multicolumn{1}{|c|}{ Optimality Index NL-2015 $^{\mathrm{a}, \mathrm{b}}$} & $\begin{array}{c}\text { Criterion for } \\
\text { Optimality }\end{array}$ \\
\hline \hline $\begin{array}{l}\text { thrombosis, preeclampsia, or HELLP syndrome present during postpartum } \\
\text { period; pulmonary embolism postpartum) }\end{array}$ & \\
\hline
\end{tabular}

${ }^{\mathrm{a}}$ The sum score of the OI-NL2015 should be adjusted for the maternal characteristics: ethnic minority, social deprivation, maternal age, and level of urbanization.

${ }^{\mathrm{b}}$ All items are available within the Netherlands Perinatal Registry except for social deprivation, which is obtained from the linkage with the database of the Netherlands Institute for Social Research. ${ }^{30}$

${ }^{c}$ New item, not present in former versions of the optimality index.

Table 2. Interrater Agreement on Optimality Between Scores From the Dutch Birth Centre Study and the Netherlands Perinatal Registry for 7 Items at Risk of Being Incorrectly Recorded $(\mathrm{N}=3655)$

\begin{tabular}{|c|c|c|c|}
\hline $\begin{array}{l}\text { Optimality Index- } \\
\text { NL2015 Item With } \\
\text { Criterion for } \\
\text { Optimality }\end{array}$ & $\begin{array}{l}\text { Optimal Score } \\
\text { in the Dutch } \\
\text { Birth Centre } \\
\text { Study }(\%)\end{array}$ & $\begin{array}{c}\text { Optimal Score in } \\
\text { Netherlands } \\
\text { Perinatal Registry } \\
(\%)\end{array}$ & $\begin{array}{c}\text { Absolute Agreement } \\
\text { Between Dutch Birth } \\
\text { Centre Study and the } \\
\text { Netherlands Perinatal } \\
\text { Registry }(\%)^{\mathrm{a}}\end{array}$ \\
\hline $\begin{array}{l}\text { No use of oxytocin for } \\
\text { augmentation of labor }\end{array}$ & 75.4 & 74.4 & $\mid 94.5$ \\
\hline $\begin{array}{l}\text { No epidural analgesia } \\
\text { for labor and/or birth }\end{array}$ & 87.2 & 86.3 & $\mid 96.3$ \\
\hline $\begin{array}{l}\text { Birth occurred in the } \\
\text { place originally } \\
\text { intended at the onset of } \\
\text { labor }\end{array}$ & 54.2 & 57.8 & || 71.8 \\
\hline No blood transfusion & 98.8 & 99.8 & 98.9 \\
\hline $\begin{array}{l}\text { No referral during labor } \\
\text { or within } 2 \text { hours } \\
\text { postpartum } \\
\end{array}$ & 53.9 & 57.8 & $\mid 93.8$ \\
\hline No urgent referral & 96.1 & 97.5 & 97.7 \\
\hline $\begin{array}{l}\text { No transfer to high-risk } \\
\text { neonatal care setting } \\
\text { within } 24 \text { hours } \\
\text { postpartum }\end{array}$ & 99.7 & 99.9 & $\mid 99.7$ \\
\hline
\end{tabular}

${ }^{a}$ Equal score in both (ie, both optimal or both nonoptimal) 